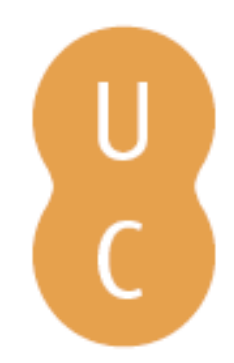

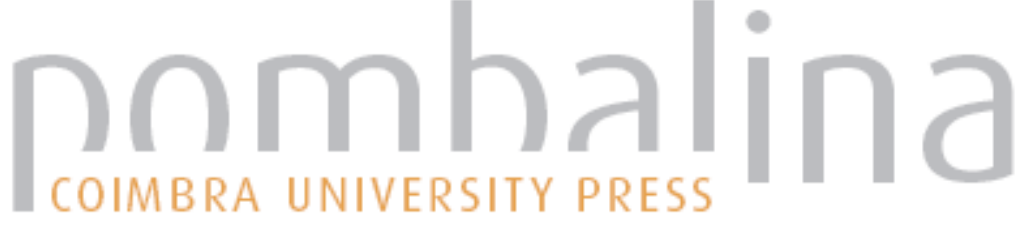

\section{A Biblioteca Geral da Universidade de Coimbra e a Faculdade de Direito}

Autor(es): $\quad$ Marcos, Rui de Figueiredo

Publicado por: Imprensa da Universidade de Coimbra

URL

persistente: URI:http://hdl.handle.net/10316.2/36990

DOI: $\quad$ DOI:http://dx.doi.org/10.14195/978-989-26-1045-0_19

Accessed : $\quad$ 26-Apr-2023 12:44:44

A navegação consulta e descarregamento dos títulos inseridos nas Bibliotecas Digitais UC Digitalis, UC Pombalina e UC Impactum, pressupõem a aceitação plena e sem reservas dos Termos e Condições de Uso destas Bibliotecas Digitais, disponíveis em https://digitalis.uc.pt/pt-pt/termos.

Conforme exposto nos referidos Termos e Condições de Uso, o descarregamento de títulos de acesso restrito requer uma licença válida de autorização devendo o utilizador aceder ao(s) documento(s) a partir de um endereço de IP da instituição detentora da supramencionada licença.

Ao utilizador é apenas permitido o descarregamento para uso pessoal, pelo que o emprego do(s) título(s) descarregado(s) para outro fim, designadamente comercial, carece de autorização do respetivo autor ou editor da obra.

Na medida em que todas as obras da UC Digitalis se encontram protegidas pelo Código do Direito de Autor e Direitos Conexos e demais legislação aplicável, toda a cópia, parcial ou total, deste documento, nos casos em que é legalmente admitida, deverá conter ou fazer-se acompanhar por este aviso. 

Tendo como pano de fundo as Comemorações dos seus 500 anos, a Biblioteca Geral da Universidade de Coimbra organizou um Congresso Internacional subordinado ao tema "A Biblioteca da Universidade: permanência e metamorfoses", que teve lugar nos dias 16, 17 e 18 de janeiro de 2014, no auditório da Reitoria da Universidade de Coimbra.

O objetivo maior desta reunião científica foi o de refletir sobre o presente e o futuro das bibliotecas que servem públicos universitários. Numa outra vertente, procurou chamar-se a atenção para a importância de que a Biblioteca se reveste, tendo em vista o progresso do conhecimento técnico e científico. Por último, o Congresso pretendeu instituir-se como oportunidade de reflexão prospetiva e como lugar de encontro entre as sensibilidades de todos os que trabalham profissionalmente com livros e com outros suportes de natureza bibliográfica.

Nesse sentido, foram apresentadas Conferências, Mesas Redondas e sessões de Testemunhos em torno de temas como o valor das bibliotecas universitárias, a biblioteca universitária em contexto; as mudanças e os desafios; a biblioteca universitária e a sociedade da informação e conhecimento; o impacto do acesso aberto na comunidade científica, e as bibliotecas digitais. 
RUI DE FIGUEIREDO MARCOS

Universidade de Coimbra

\section{A B IBLIOTECA GERAL DA UNIVERSIDADE DE COIMBRA E A FACULDADE DE DIREITO}

No âmbito das comemorações que assinalaram os cinco séculos da Biblioteca da Universidade de Coimbra, realizou-se, por benfazeja iniciativa do seu ilustre Director, o Senhor Doutor José Augusto Cardoso Bernardes, um Congresso Internacional subordinado ao título "Biblioteca da Universidade: Permanência e Metamorfoses". Correspondendo a um seu gentilíssimo convite, presidi a uma das sessões desse Congresso. Um convite, aliás, cuja pronta aceitação me soava a imperativo de consciência. Frequento a Biblioteca da Universidade de Coimbra há cerca de quarenta anos e aí colhi abundantes ensinamentos que viriam a alimentar as minhas investigações e o meu magistério jurídico. É uma dívida que nunca se pagará.

Diodoro da Sicília deu-nos conta de que uma antiga biblioteca era fechada por uma porta na qual se lia a seguinte inscrição: "Remédios para a Alma». Não me disponho a discorrer sobre os eventuais remédios para a alma que a Biblioteca Geral da Universidade de Coimbra poderá encerrar. Todavia, já não devo calar os dois propósitos essenciais que animam as breves considerações que se seguem.

O primeiro é, antes de tudo, o de apresentar o orador que, seguramente, concitará a admiração de quantos acudiram a este acto. Escutaremos o testemunho vivo de quem se tornou um frequentador assíduo de bibliotecas e, em especial, da nossa preciosa Biblioteca da Universidade de Coimbra, desvelando algumas páginas cativantes do seu labor disquisitivo. Aludo ao Doutor João Gouveia Monteiro, distinto professor da Faculdade de Letras da Universidade de Coimbra. 
Só reconhece quem conhece. E eu conheço bem o Doutor João Gouveia Monteiro. A nossa amizade alonga as suas raízes aos bancos da Escola. Ora, as amizades que se constroem nos bancos da Escola são aquelas que mais resistem às vicissitudes da vida. São aquelas que nos acompanham até à viagem de onde não há regresso.

O Doutor João Gouveia Monteiro tem-se devotado à história medieval europeia e, sobretudo, à história militar antiga e medieval. Uma disciplina de que se tornou um expoente cimeiro no plano nacional e além-fronteiras. É um investigador cujo talento rivaliza, em grandeza, com a sua operosidade. João Gouveia Monteiro conserva-se agarrado ao trabalho como uma sentinela à sua espingarda. Nada o consegue distrair dos seus planos de estudo meticulosamente traçados. Não admira, pois, que seja um académico múltiplas vezes galardoado.

Parece que todas as migalhas do seu tempo guardam um préstimo. Daí que, sem conceder benevolências ao descanso, ainda logrou exibir os rostos institucionais de Pró-Reitor para a Cultura e de Director da Imprensa da Universidade de Coimbra. João Gouveia Monteiro tem o futuro por si.

Não posso omitir, na circunstância que passa, a minha condição de Director da Biblioteca da Faculdade de Direito de Coimbra. Aproposita-se o ensejo de mostrar os fortes laços que prendem a Faculdade de Direito de Coimbra à Biblioteca Geral da sua Universidade.

A Biblioteca da Faculdade de Direito de Coimbra celebrou em 2011 o seu Primeiro Centenário. Escusado será enaltecer a posição destacada que assume no contexto das bibliotecas jurídicas, quer em Portugal, quer na Europa. Mas já se impõe não esquecer o valioso contributo que, na primeira década do século XX, a Biblioteca Geral da Universidade deu à sua construção.

A Biblioteca da Faculdade de Direito de Coimbra surgiu com o sentido que lhe imprimia a visão do magistério do direito de 1911. Professava a crença inabalável de que o ensino não devia exaurir a actividade de um docente de Direito. O universitário precisa sempre da investigação para fazer respirar o seu ensino. Uma teia científico-cultural e didáctica que se entretece de aquisições recíprocas. A este propósito, a Reforma de 
1911 exibia uma cintilância bifronte. De um lado, expor a ciência feita e, de outro, mostrar como se faz a ciência.

As sementes sopradas de além-fronteiras voejaram até ao nosso país. Nas universidades alemãs, os seminários constituíram exemplos notáveis de progresso científico. Em Berlim, destacava-se o seminário de direito criminal dirigido por Von Liszt, em Leipzig avultava o seminário de economia política sob a orientação de Karl Bücher e, em Heidelberg, ganhou projecção internacional o seminário de direito público do famoso Jellineck. O modelo dos seminários jurídicos passou à Itália, designadamente a Pisa e a Pádua e fez carreira na França, em especial, na Faculdade de Direito de Paris, com as chamadas "Salas de Trabalho». Já haviam então alcançado enorme renome a sala de trabalho de direito penal, dirigida por Garçon, de direito público, orientado por Larnaud e de direito romano que contava com o prestígio de $C u q$ e, sobretudo, Girard.

$O$ voto de alimentar a docência com a investigação surdiu estupendas consequências na Faculdade de Direito de Coimbra. A Reforma de 1911 transplantou o modelo estrangeiro, criando um estabelecimento congénere a que deu o nome de Instituto Jurídico.

Assumia todos os contornos de um centro de actividade científica, considerado de suma utilidade a professores e a alunos. Aí se tenderia a implantar um ambiente de fervilhante debate de ideias.

Os trabalhos do Instituto Jurídico consistiam em exercícios, conferências e discussões científicas propícias ao domínio dos métodos de investigação. Do ponto de vista organizativo, o Instituto Jurídico integrava quatro secções, em harmonia perfeita com o mosaico dos grupos de disciplinas. Eis as quatro secções: a $1 .^{a}$ de História do Direito e de Legislação Civil Comparada, a 2. ${ }^{a}$ de Ciências Económicas, a 3. ${ }^{a}$ de Ciências Políticas e a $4 .^{a}$ de Ciências Jurídicas. Em cada uma delas, surgiram dois tipos de cursos. Um era elementar, para principiantes. O outro, crismado de curso superior, destinava-se à preparação de estudos originais. Como apoio fundamental à missão que lhe foi assinalada, o Instituto Jurídico passava a dispor de uma biblioteca privativa. A Biblioteca da Faculdade de Direito.

A Reforma de 1911 revelou-se deveras audaciosa. A audácia começou, desde logo, no voto primordial de restituir a Escola à sua verdadeira 
missão. Em tal óptica, promoveu a separação entre a função docente e a função de julgamento. A primeira pertencia naturalmente à Faculdade e a segunda devia caber a representantes do Estado. O exame tornara-se objecto de infinito culto. O professor sacrificava ao exame o tempo, a energia e até a tranquilidade de espírito necessários à investigação científica. Por seu turno, o estudante via o professor pelo óculo do exame, ou, se se preferir, o exame personificado no professor, o que podia perturbar um saudável ambiente de cordialidade. Impunha-se, por conseguinte, descontaminar a atmosfera da Faculdade de Direito, proporcionando ao professor o sossego mental indispensável à função docente e, do mesmo passo, libertando o espírito do estudante das imagens incómodas que nele desencadeavam as vestes carregadas do professor-examinador. Um novo ambiente académico reclamava outras condições de estudo.

Revelámos o sentido matricial da Biblioteca da Faculdade de Direito. Caminhar de mãos dadas com o Instituto Jurídico, alimentando a investigação, foi o seu lema radioso.

Um aspecto que ressalta com nitidez logo no primeiro fôlego da Biblioteca. Em Congregação de 20 de Novembro de 1911, o Director da Faculdade, o Doutor António Lopes Guimarães Pedrosa lembrou a necessidade de eleger, nos termos do artigo 83..$^{\circ}$ da Reforma dos Estudos Jurídicos, um professor para bibliotecário privativo da Faculdade. A escolha recaiu no Doutor Álvaro Machado Vilela. Por sinal, aquele que fora o grande mentor da Reforma de 1911. Seguramente, uma benquista coincidência.

De imediato, por alvitre do Director da Biblioteca, constituiu-se um Conselho para o coadjuvar na sua difícil missão edificadora. O desenho escolhido não podia ser mais coerente. Na verdade, o Conselho da Biblioteca integrava um representante de cada um dos quatro grupos de disciplinas em que a Faculdade se encontrava dividida, o que correspondia exactamente às quatro secções que compunham o Instituto Jurídico.

Deputaram-se, pelo $1 .^{\circ}$ Grupo que recebera a intitulatio de História do Direito - Legislação Civil Comparada, o Doutor Artur Montenegro, pelo 2. ${ }^{\circ}$ Grupo, o de Ciências Económicas, o Doutor Marnoco e Souza, pelo $3 .^{\circ}$ Grupo, o de Ciências Políticas, o Doutor Guimarães Pedrosa e pelo $4 .^{\circ}$ Grupo, reservado às Ciências Jurídicas, o Doutor Guilherme 
Moreira. A Faculdade, mostrava, assim, o envolvimento das suas figuras de primeira grandeza na construção interior da Biblioteca.

Mas não se quedou por aqui. A Faculdade, a um pronto, deslocou uma importante parcela do seu orçamento para a Biblioteca. Nada menos de um conto de réis se destinou à compra de livros e à assinatura de revistas científicas. À luz da distribuição das receitas, percebe-se que as missões científicas ao estrangeiro, as obras nas salas do Instituto Jurídico e, sobretudo, o desenvolvimento da Biblioteca representavam os lances prioritários da política da Faculdade. No fundo, os votos radiosos na internacionalização dos horizontes académicos e na investigação permanente acomodada em salas amáveis.

Os sinais de apreço pela Biblioteca surgiam a cada passo. O Conselho da Faculdade, por diversas vezes, decidiu reforçar a verba que se consignara à aquisição de livros e à assinatura de publicações periódicas. Tal sucedeu, por exemplo, na Congregação de 5 de Maio de 1914.

Machado Vilela exerceu o cargo de Director da Biblioteca da Faculdade de Direito com inquebrantável entusiasmo, como era seu timbre. E, no fim de 1913, anunciou uma diligência que iria conhecer o maior significado para a nova Biblioteca. Machado Vilela solicitara a catalogação das obras dos praxistas que então se encontravam quase perdidas, reputando-se incontestável o seu interesse para os alunos de Direito. A cedência das obras dos praxistas à Biblioteca da Faculdade de Direito havia sido já prometida pelo Director da Biblioteca Geral da Universidade de Coimbra, cargo que, ao tempo, era exercido pelo Doutor Marnoco e Souza.

Em Congregação de 4 de Novembro de 1914, Machado Vilela voltou a insistir na transferência das colecções dos praxistas inseridas na Biblioteca chamada de "S. Pedro». Guilherme Moreira, Reitor da Universidade, declarou que faria o que entendesse conveniente no sentido de ver satisfeito o pedido da Faculdade.

Compreende-se o voto continuado de Machado Vilela. Quando o Director da Biblioteca empregava a designação praxistas, não visava apenas os autores que versavam a prática forense ou mesmo notarial. Sob a capa larga do qualificativo de praxistas, abrigava os chamados reinícolas, ou seja, abrangia todos os antigos jurisconsultos, sem atender à natureza 
da sua produção científica. Por isso, a Biblioteca de S. Pedro incluía um largo espectro de autores, sobretudo pertencentes aos séculos XVI, XVII e XVIII. Enfileiravam-se civilistas, canonistas, comentadores do direito pátrio, casuístas, tratadistas e repertoristas.

O desejo de Machado Vilela concretizou-se. Os praxistas habitam agora a nossa bonita Sala Chinesa. Encontram-se devidamente tratados e acomodados. Constituem um fundo indispensável à pesquisa histórico-jurídica nos planos privatista e publicista, bem como ao pensamento filosófico e político, Razão sobeja para que a Faculdade de Direito tribute uma homenagem à Biblioteca Geral da Universidade de Coimbra.

O apego fervoroso à Biblioteca de Direito transpareceu de um episódio histórico deveras expressivo. Corria o ano de 1922. Ainda no rescaldo na Primeira Guerra Mundial, a Reitoria da Universidade de Coimbra solicitou à Faculdade de Direito que se pronunciasse acerca do que entendia dever reclamar à Alemanha a título de reparações en nature, de molde a serem incluídas na lista a apresentar pelo governo português.

E a Faculdade decidiu de forma inequívoca. Apontou, como pretensões cimeiras, as obras fundamentais da bibliografia jurídica alemã, a par da vinda a Coimbra de quatro professores de Direito, um por cada uma das secções em que se dividia a Faculdade, considerando-se indispensáveis um romanista e um criminalista.

Do rosto da sua Biblioteca extraiu-se também um certo modo de ser da Faculdade de Direito. Foi construída com exigências de sentido. Desde logo, incentivar a formação daquilo que se designa por jurista integral. Por isso, observamos, sem espanto, que parte da estantaria da Biblioteca da Faculdade se encontra povoada de livros não jurídicos. Muito do que é direito explica-se, genética e funcionalmente, por aquilo que não o é. O direito não irrompe por actos solitários do génio, nem desaparece, fugidamente, na noite do acaso. Insere-se sempre no recortado contexto constituinte e reconstituinte. A própria natureza do direito reclama que o seu ensino o entenda vinculado à existência cultural e histórica do homem.

Não carrear recursos para aquisição de livros implica amarelecer uma biblioteca. Centralizar o sistema de compras com peias burocráticas significa empecer a sua dinâmica. Governar uma instituição não é apenas 
medir e calcular. Menos será amortalhar os ânimos com regulamentos de pendor sufocante.

De um ângulo diverso, vários juristas e não poucos professores da Faculdade de Direito de Coimbra inscreveram o seu nome, a título definitivo, na história rútila da Biblioteca da Universidade de Coimbra. Pretendo aludir àqueles que pertencem à galeria dos ilustres Directores da Biblioteca Geral da Universidade de Coimbra.

Cingirei as minhas observações às três últimas centúrias. Da constelação dos juristas de setecentos, ascenderam a Directores da Biblioteca da Universidade de Coimbra António Ribeiro dos Santos (1777-1796) e Ricardo Raimundo Nogueira (1798-1802). Ambos se notabilizaram no quadro da Reforma Pombalina da Universidade e ambos receberam a incumbência de redigir compêndios adequados às novas directrizes pedagógicas e científicas. Vem de molde encarecer o desvelo do Marquês de Pombal pela livraria jurídica, ao ponto de, numa carta de 25 de Fevereiro de 1774, chamar a atenção do Reitor-Reformador D. Francisco de Lemos para o envio que ele próprio promovera de um conjunto de «espécies» respeitantes à História do Direito Pátrio. Uma disciplina que considerava indispensável para os mancebos se tornarem capazes «de bem entenderem as Leys, e de bem as executarem».

António Ribeiro dos Santos envolveu-se numa viva polémica com Mello Freire. Foi suscitada pela crítica torrencial que dirigiu ao projecto de Código de Direito Público da autoria de Mello Freire e que visava reformar o livro II das Ordenações Filipinas. Devido a este seu espírito meticuloso e regrador, não admira que Ribeiro dos Santos tenha esquadrinhado um importante regimento da Livraria da Universidade de Coimbra, onde, além de definir os fins da instituição, disciplinava a organização da biblioteca. O professor da Faculdade de Leis Ricardo Raimundo Nogueira recebeu e valorizou o legado de Ribeiro dos Santos na Biblioteca da Universidade de Coimbra. Em 1802, abandonou o cargo, para assumir o lugar de Reitor do Colégio dos Nobres, ascendendo depois os mais altos postos da hierarquia do Estado.

No século XIX, guindaram-se a Directores da Biblioteca Geral da Universidade de Coimbra os professores da Faculdade de Direito Joaquim dos 
Reis (1802-1810), Manuel de Serpa Machado (1834-1858), Justino António de Freitas (interino, 1840 - após 1849), Basílio Alberto de Sousa Pinto (1849-1858) e Bernardo de Serpa Pimentel (1858-1894). Cada qual, a seu modo e na sua circunstância, contribuíram para o engrandecimento da Biblioteca da Universidade de Coimbra.

A Biblioteca Geral da Universidade de Coimbra, no século XX, conheceu à frente dos seus destinos duas das mais prestigiosas figuras da Faculdade de Direito de Coimbra. Em mente temos José Ferreira Marnoco e Souza (1913-1915) e Guilherme Braga da Cruz (1971-1977). Julgo não cometer nenhum delito de inconfidência se revelar um sinal expressivo do imenso carinho que o Doutor Guilherme Braga da Cruz nutria pela Biblioteca Geral da Universidade de Coimbra. Encerra-o uma carta de 23 de Maio de 1961 que o Doutor Braga da Cruz dirigiu ao então Ministro da Educação Nacional, o também professor de Coimbra, Doutor Manuel Lopes de Almeida. Estava em causa a aceitação do cargo de Reitor da Universidade por parte de Braga da Cruz. O Mestre de Direito ousou formular três condições. Uma das que reputava essenciais para assumir o posto cimeiro respeitava precisamente à resolução do importante problema do quadro da Biblioteca Geral da Universidade de Coimbra. Mais. Por ocasião da passagem do primeiro aniversário da abertura ao público do novo edifício da Biblioteca Geral da Universidade, o Doutor Guilherme Braga da Cruz enviou, em 19 de Março de 1963, uma missiva ao Dr. César de Oliveira Pegado, ilustre bibliotecário-chefe, em que mostra bem o elevado apreço que tinha pela Biblioteca Geral e pelo seu corpo de funcionários. Eis as belas palavras do Doutor Guilherme Braga da Cruz: "Sabe Vossa Excelência com quanto carinho e entusiasmo acompanhei, no ano lectivo findo, os preparativos para a abertura da Biblioteca; com quanto orgulho e desvanecimento pelo mais modelar de todos os serviços universitários acompanhei os nossos convidados na visita inaugural e levei depois disso à Biblioteca todos os mais ilustres visitantes da Universidade durante o meu efémero reitorado; e quanta consideração e estima fiquei tendo pelo excelente corpo de funcionários de que a Biblioteca dispõe e de quem sempre tantas provas de dedicação recebi. Nada me poderia, pois, sensibilizar mais, neste dia em que a Biblioteca nova completa um 
ano ao serviço, do que a grata e honrosa gentileza que Vossa Excelência e os funcionários sob as suas ordens quiseram ter para comigo e pela qual me confesso imensamente reconhecido».

Enfim, importa rematar este breve e leve apontamento.

A agonia do Estado social magoa. É a paz íntima de todos nós chamados a sacrifícios imprevistos que se inquieta irremediavelmente. É o raciocínio das pessoas bem dispostas e dispostas ao bem que se tolda. Precisamos de esteios humano-culturais.

O estudo dos livros, proclamou-o Séneca, constitui singular refrigério para a tribulação. Um dado da experiência de vida que o nosso erudito quinhentista Frei Heitor Pinto encareceu com todas as suas forças, através de um sincero desabafo: "como me sinto dela acossado e cercado de perigos e entalado com dificuldades logo me socorro aos livros como às asas de Dédalo, para poder sair do cárcere das angústias e voar no alto». Do cimo dos seus cinco séculos de história, a Biblioteca Geral da Universidade de Coimbra constitui, fora de dúvida, uma excelente base para levantar voo. 
José Augusto Cardoso Bernardes é Professor da Faculdade de Letras da Universidade de Coimbra e Diretor da Biblioteca Geral da Universidade

Ana Maria Eva Miguéis é coordenadora do Serviço Integrado das Bibliotecas da Universidade de Coimbra

Carla Ferreira é bibliotecária nos Serviços de Biblioteca e Documentação da Faculdade de Letras da Universidade de Coimbra. 


\section{Série Documentos}

Imprensa da Universidade de Coimbra

Coimbra University Press

2015

C •

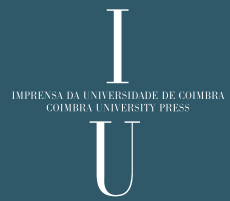

